\title{
PROCESSO E DIREITO ADMINISTRATIVO
}

\author{
Manoel de Oliveira Franco Sobrinho \\ Professor na Faculdade de Direito da \\ Universidade do Paraná
}

O estudo do procedimento administrativo ou da marcha dos negócios chamados contenciósos, traz uma dúvida fundamental:

- é possível, dentro da estrutura do Direito Administrativo, traçar linhas normativas de atividade processual?

Ludwig Spiegel, com alguma razão de ordem jurídica, acredita que não há disciplina com iguais vantagens que dispute ao Direito Administrativo, estudo mais sério da teoria do procedimento (1).

Sem dúvida: qualquer ramo do direito possui distinto modo de aplicação e método próprio de investigação da realidade jurídica.

A questão para Spiegel está no saber se o procedimento administrativo é sucetível ou digno de observação teórica!

$O$ ideal por certo seria a condensação de regras administrativas numa sistemática especial de processo, caracterizando-se novo aspecto do direito positivo, - tal como acontece na esfera do Direito Processual Civil ou Penal (2).

1) Ludwig Spiegel - DERECHO ADMINISTRATIVO - Ed. Labor; Temistocles B. Cavalcanti - CóDIGO DO PROCESSO ADMINISTRATIVO - Rev. do Serv. Público - Vol. III - n. 2.

2) Evoquem-se as razóes dos debates entre Thibaud e Savigny à propósito da necessidade da codificação dos modos de aplicação das leis e normas jurídicas. "A tendência do nosso século e para a codificação, para a remissão em um texto único, pelo menos das normas gerais do direito" (T. B. Cavalcanti - ob. cit. - Rev. do Serv. Público). 
Nosso autor Ludwig Spiegel interroga com frequência sôbre o sentido do procedimento administrativo, - sôbre o espírito dos seus princípios orgânicos basilares, - para aconselhar da sua importância junto à teoria geral do processo.

0 modo de ser do direito, bem o sabemos, está na processualística. Processo é fato, processo é - fato-vida, - fato expressão da realidade jurídico-positiva (3).

A atividade que se exterioriza, a prática cotidiana dos textos de lei empregados para cada caso diferente, o contacto com essa realidade jurídico-positiva, - dão formalística e sistema ao direito e sentido próprio ao pensamento que o orienta.

E o processo é essa maneira de ser diferente, - aqui obedecendo determinadas normas, lá seguindo outras idéias, - tudo numa forma de proceder expressional da condição social-jurídica.

Eis o objeto da ciência ou da processualística científica :

- aplicação de princípios jurídicos, realização do direito através métodos específicos, - aplicação e realização por experiência e também investigação do princípio jurídico de vida social, revelando na exteriorização as diferentes etapas do pensamento humano ou da afirmação do querer jurídico. (4)

\section{II}

Podemos afirmar:

- o Direito Administrativo em sua função de Estado, representando poder público e atuação social dêsse poder, com a complexidade de um organismo que é quasi todo direito,

3) A finalidade do processo é o esclarecimento da verdade (Ver ORGANIZAÇÃO E SISTEMA DO PROCESSO ADMINISTRATIVO - Exposição de Motivos de Manoel de Oliveira Franco Sobrinho - Caixa Econômica Federal do Paraná).

4) “A prática é a melhor pedra de toque onde se apura o merecimento de um código (Oliveira Santos - DIREITO ADMINISTRATIVO E CIÊNCIA DA ADMINISTRAÇÃO - ed. 1919 - p. 262); "é um passo no aperfeiçoamento científico..." (C. S. Barros Junior - A CODIFICAÇÃO DO DIREITO ADMINISTRATIVO - Rev. de Dir. Administrativo - vol. 18 - p. 2). 
com a estruturação própria imprescindível aos fins de serviço público, - em vitalidade de ação jurídica supera em dinamismo o processo civil e o processo penal.

Idênticos problemas de objetivação jurídica ou de afirmação do ideal de justiça aqui existem, quiçá mesmo com bem maior intensidade. $\mathrm{Na}$ vida da história do direito há sempre uma maneira de ser, - o que evita não poucas vezes a tendência filosófica para o abastracionismo juríuico.

Há, - não deixamos de concordar, - um sistema jurídico de categorias delimitadas, agindo por sôbre campos diferentes e visando fins diversos. Cada uma dessas categorias possue o seu especial senso jurídico, - não se confundindo com as demais em razão da diferença de finalidade. Ainda que persista concordância de meios e identidade de fins, - a forma de ser é diversa, - outro é o modo de proceder.

Podiamos está claro enquadrar o procedimento administrativo no liimte da linha normativa judiciária geral. Atualmente, afóra regras especiais de regulamentação, - regras especiais que determinam atividade processual própria, - o administrativo não codificado tende deixar-se influenciar pela tradição do judiciarismo.

Mas o modus procedendi é sempre expressional. Repetimos sempre: o processo é a expressão da verdade real. A ação variável do direito cria meios e usa de recursos, - meios e recursos - no mais das vezes extra-judiciais, - de métodos nào judiciários (5).

Se não designarem os árbitros, no prazo legal, a escolha ser enquadrados dentro em única categoria, a própria proces-

5) Manoel de Oliveira Franco Sobrinho - ORGANIZAC̃̃O E SISTE. MA DO PROCESSO ADMINISTRATIVO: "Estabelecidos os princîpios gerais de administração ou de govêrno, impõem-se naturalmente a necessidade do processo de execução, - do processo administrativo, - da norma de atividade processual, - o modo de fazer, de agir, ae realizar o objeto do serviço, - seja o serviço de natureza pública ou privada" (trab. cit. - p. 3). Da mesma forma Temistocles Cavalcanti: "o modo de ser do direito está na processualística" (trab. cit. - loc. cit.), 
sualística desapareceria por desnecessidade do método de aplicação do dịreito. Óra o direito é fenomenologia, - e como tal produto da vida nos seus mais variados aspectos, tendências, aspirações e ideais...

Tratando-se possìvelmente de uma jurisdição especial dentro de limites pré-fixados pela prática regulamentar, a atividade-procedimento litigiosa ou não, é indubitàvelmente do ponto de vista teórico tão importante quando a civil ou penal.

Onde existem fins administrativos, existe por certo evidenciação de meios, - meios consequência imediata dêsses fins.

Spiegel observa com razão que não é possível alguém ou ninguém subtraír-se da atividade administrativa do Estado.

Aqui está para ilustrar o maior argumento de Ludwig Spiegel :

O processo civil e penal pertencem à patologia, a atividade administrativa corresponde à fisiologia da vida jurídica; a patologia e a terapêutica só possuem interêsse para os enfermos.

III

Continuemos para argumentar.

A célebre teoria de Walter Jellineck afirma e acredita na existência de atos administrativos bi-laterais (6).

Ato administrativo bi-lateral é, para o constitucionalista alemão, aquele que necessàriamente está composto de duas partes iguais : a declaração da vontade do particular e outra declaração jurídico-pública do Estado.

Para Fritz Fleiner, - outro ilustre jurista da escola alemã moderna, - é nulo todo ato administrativo onde faltar a manifestação declarada da vontade particular.

6) Assim é Rafael Bielsa quem afirma "a obra de Jellineck é um estudo sistemático, cujos caracteres mais salientes são a amplitude da exposição doutrinária, sua correlação com o direito positivo e, sobretudo, as prolixas referências bibliográficas". (Ver ESTUDIOS DE DERECHO ADMINISTRATIVO - ps. 138/9); ou veja-se Jellineck - SISTEMA DE DIREITO PUBLICO SUBJETIVO - trad. italiana ed. Milão, 1912. 
Admitindo os enunciados de Jellineck e Fleiner, chegamos à conclusão seguinte:

- para a permanência da unilateralidade do ato administrativo ou da bi-lateralidade aceita e consagrada por êsses autores, será preciso todo um processo que se perfaz no encontro das vontades opostas em contacto para um mesmo fim.

A diferença de cunho doutrinário, que vamos encontrar de uma análise comparativa frontal com a processualística civil e criminal, não é outra que esta:

- a realização do Direito Administrativo incumbe às autoridades administrativas.

No caso o procedimento, - ou processo conforme significado legal ou técnico do vocábulo, - está na forma pela qual a administração realiza os seus fins.

Não pode haver por conseguinte, - é Spiegel quem ensina, - um MODUS PROCEDENDI único para as diferentes autoridades, - senão uma série de MODOS distintos.

A variedade dos fins provoca a diferença dos meios.

O processo civil, como exemplo, sempre recai, ou sôbre um direito real como a propriedade, ou sôbre uma obrigação. Não considera êle, de forma alguma, a atividade funcional do Estado.

Outros vão mais adiante como Menzel, afirmando a não possibilidade de existência de um só tipo normal de procedimento no tocante mesmo à administração pública.

Daí a complexidade do procedimento administrativo com relação ao estudo da teoria geral do processo.

Não há contestar:

- as relações contratuais entre Estado e particular carecem de maior maleabilidade jurídico-processual (7).

7) Tito Prates da Fonseca - DIREITO ADMINISTRATIVO - Parte Final; José Matos de Vasconcelos - DIREITO ADMINISTRATIVO - vol. II; Temistocles B. Cavalcanti - INSTITUIÇõES DE DIREITO ADMINISTRATIVO - vol. II. 
Para o direito civil, o contrato está seguro à dispositivos codificados em tábua de lei. Fóra das disposições legais não encontra justificação nem guarida, - é ilegal e ajurídico.

O contrato que a administração realiza com o particular sòmente no concernente à teoria geral do direito acompanha o modêlo tradicional dos contratos civis. Quanto à forma, varia com o fim. Quanto ao meio, ao procedimento, ao conteúdo ou à matéria, - naturalmente estará adstrito a êsse fim.

Sabemos pela idéia que possuimos de conceito de contrato que o instituto jurídico é consequência de duas vontades, vontades essas que revelam atos, - mas atos de ambas as partes. Intervindo a administração, então a ato administrativo aparece sempre na forma diversificada, que traz a complexidade da sua melhor conceituação.

Com o contrato administrativo, onde há dois atos diferentes que se correspondem, o ato do Estado aparece subordinado a leis e regulamentos, enquanto o ato individual, caracterizando o jus privatista, é puro ato de direito privado. Não existe dúvida: a predominância do objeto exterioriza a espécie de contratação.

Spiegel, tratadista que na questão espalhou luzes do seu conhecimento especializado, é de opinião que à ciência do Direito Administrativo cumpre importante missão em virtude da enorme variedade do mesmo procedimento administrativo:

- em primeiro lugar porém terá de dedicar atenção ao estudo das distintas classes de procedimento, - e realizar o mesmo trabalho que a teoria processual civil empreendeu com raro êxito.

As diferentes classes de procedimento em matéria de águas, de concessões industriais ou fixação de impostos, elaboram-se teòricamente. Trata-se, portanto, de procurar descobrir as leis do procedimento, - estabelecendo assim bases de ciência processual ainda não existente, - de uma ciência que se ocupe 
do PROCEDIMENTO PRÓPRIO, - e não das figuras caracterizadas do PROCEDIMENTO CIVIL OU CRIMINAL.

Mas também não há como querer negar:

Existem seguramente certos problemas de processualistica que se resolvem através a mesma FORMA, - e se resolvem para todos os tipos de procedimento.

Está, pois, sem grande dificuldade, o problema situado e definido. Do século desenove para cá, as investigações na esfera do político-social tão sòmente aumentaram de importância o processo civil. No terreno da ciência da Administração, o que se realizou foi isto: coleta de dados dispersos sem a menor preocupação de sistema ou de metodologia.

\section{V}

Está claro para os que adotam a tese de James Goldschimidt:

- o conjunto de normas jurídicas que regulam o processo Civil, - é direito Processual Civil (8).

Assim também com o Direito Administrativo:

- a série de leis, regulamentos, portarias, notificações, informações, - fazem processo administrativo.

A instrução poderá ser igual no sentido do acabamento decisório para ambas as formas de procedimento, - tanto a processual administrativa, como a processual civil.

Não há como discutir: processo é método.

O processo civil para Goldschmidt é método seguido pelos tribunais, ou então:

1) - é procedimento, - caminho concebido desde a Idade Média, - para aplicação do direito;

2) - o objeto é o exame do direito ou da pretenção do autor contra o Estado, buscando obter tutela jurídica mediante sentença favorável e consequente execução da mesma.

8) Ver a grande obra de James Goldschimidt - DERECHO PROCESSUAL CIVIL - Ed. Labor. 
O objeto geral do processo está na conquista da tutela jurídica. Ou tutela para esclarecimento da verdade ou melhor aplicação da lei, - em se tratando do procedimento administrativo (9).

Bulow e Kohler definem àsperamente a teoria de que o direito Processual aparece como relação jurídico-pública. Mas Goldschimidt limita para melhor conceituar, caracterizando-o como relação jurídica estabelecida entre partes litigantes e 0 poder que julga.

No Direito Administrativo encontra essa teoria cordial acolhida. 0 indivíduo tão sòmente terá relação com o poder de Estado quando recorre de ato já realizado pela administração pública (10).

Alguns defendem a bilateralidade dessa relação. Outros pregam a trilateralidade, - desde que a relação se estabelece entre demandante, demandado, e quem sabe o tribunal competente.

Ao Direito Administrativo porém só interessa a bilateralidade de relação jurídica. Não há nunca demandado, pois, o demandado no caso confundir-se-ia com a figura do poder que julga e pode executar.

Aceitamos como evidência:

- o método para o estudo ou julgamento, ou mesmo aplicação, - das dicisões do poder público na parte formalística muito pouco diferem do procedimento civil.

As diferenças de fundo e de forma quando surgirem vamos encontrá-las por fôrça do imperatívo do fim necessário. Ou no determinativo de relação de direito, defendido em teoria por Kohler.

9) O objeto do processo está pois na prevenção à tutela jurídica. Enfeixado na órbita do Direito Administrativo, é o que positivamente visa: - recurso judicial, ordinário ou extraordinário, contra atos do Estado que exorbite da sua ação ou firam direitos consagrados em lei" (ver Manoel de Oliveira Franco Sobrinho - DA POSIÇÃO JURIDICA DO DIREITO PROCESSUAL ADMINISTRATIVO - in DIREITO - vol. II).

10) ... o Direito Administrativo subordina os indivíduos à administração (ver L. Spiegel DERECHO ADMINISTRATIVO - p: 15). 
Não obstante um princípio permanece exato:

- é uma só a noção fundamental de processo.

A unidade se desmembra através objetivos diferentes, o fim, muitas vezes, justificando os meios.

\section{VI}

Assim entendemos:

0 procedimento, - traçando linha histórica da ciência, ganhou estrutura na sistematização do direito romano.

0 magistrado julgando sumàriamente, in jure, e o julgamento especial, detalhado, por meio de provas, de defesa de parte, in iudicio, - foi tôda processualística da antiguidade, isso em leis, ou em maneiras objetivas de proceder jurídico.

Arremata Goldschimidt:

"O procedimento começa com a in ius vocatio do demandando por parte do demandante. Depois de ouvidos os contendores, o pretor concede ao demandante da ação, a contestação do demandado por escrito. $\mathrm{O}$ ato da litiscontestação é, pois, a definitiva edere actionem, do demandante e o accipere iudicium da parte do demandado, - constituindo verdadeiro contrato, segundo Wlassak" (11).

O direito Romano ficou com o merito de através legislação especial formular em princípios breves a marcha processual das ações em juizo. Também o primeiro recurso no Direito Administrativo reconhece as vantagens da contestação. Os tribunais administrativos quando podem desfazer a validade de um ato, podem também em vista de comprovantes apresentados mantê-lo intacto.

O processo administrativo não era porisso totalmente desconhecido do direito Romano. Havia perturbando seu desenvolvimento normativo o autoritarismo de império do poder público. $O$ episódio recurso, era como sempre foi, o mesmo das ações eivis e penais.

11) Goldschimidt - ob. cit. 
Prejudicava naturalmente a luta nos pretórios a predominância do espírito político da época. Govêrno e assembléia legislavam para dizer a palavra da verdade jurídica ou a verdade jurídica do interêsse de casta social.

$\mathrm{E}$ dessa forma sòmente de longe um ato de violência da administração, - como por exemplo a tributação excessiva ou o rigor de lei fiscal violentamente aplicada, - era reformado na base do protesto havido ou na forma do recurso interposto.

\section{VII}

$\mathrm{O}$ direito Germânico, - ao mesmo tempo mais antigo e mais moderno que o Romano, - aceitava a existência de processo, desde que houvesse: a citação por intimação do demandado por parte do demandante.

A inicial do processo estava nisto: a citação por intimação. Feita a alegação jurídica da citação, o processo germânico convidava o demandado para a possível contestação.

Novidade nenhuma, ao que parece...

Contrário porém à lei romana, fundamentada a denúncia e ouvida a parte atacada, o juiz estava capacitado a decidir.

As razóes eram orais. A defesa estava na contestação da denúncia. Isso tudo evitando o formalismo das leis românicas, aquele contrato de litiscontestação lembrado por Goldschimidt.

$O$ ilustre tratadista bem demonstra a austeridade do processo romano face ao germânico, - processo mais dependente da vontade das partes, do arbítrio dos juizes.

Mas na Itália completou-se a fusão da processualística romana com a processualística germânica. Assim a jurisdição é total e está em mãos do poder público, - sob a direção de funcionários de Estado, orientação de peritos e decisão dos entendidos em lei.

Foi na Itália onde houve início a essa espécie universal de processo, dominante hoje entre os povos civilizados do ocidente.

A regra yeral não será outra que esta: 
- a petição do demandante cita com prazo marcado o demandado. A duração da marcha processual, - o tempo processual decorrido pelo procedimento, - traz necessàriamente a obrigatòriedade do registro preciso das incidências ocorridas.

○ processo será aqui a expressão da verdade jurídica, a expressão do fato jurídico. Urge que revele, através do curso de diferentes peças afirmativas ou negativas, onde e com quem está o direito ou a realidade da justiça para melhor aplicar-se a lei.

Evoquemos, mais uma vez, a lição de James Goldsmidt.

- mas a "sentença poderia ser impugnada como iníqua por apelatio, de onde crivava no grau mais avançado a querela nullitatis, pela qual se pedia a anulação da mesma sentença".

Chegamos à evidência do processo como exteriorização legal-objetiva de um fato passado e regularmente reconstituido para conhecimento de efeito da aplicação da lei.

\section{VIII}

0 tradicional processo francez apresenta características diferenciais bastante expressivas. Os princípios que ainda lhe são determinantes nasceram de profunda consciência política chegada às necessidades sociais e humanas.

Convém tomar nota: em França constituem realidade a ação dos tribunais de droit commun e dos tribunais d'exception.

A exemplo do direito Romano, mesmo Germânico e ítalo-Canônico, a justiça era uma só, - tão sòmente uma só. Enquanto que em França a distribuição por instâncias de direito comum ou de exceção caracterizavam normas objetivas de procedimento processual (12).

Mas o processo era o civil. Era o processo civil para todos os casos onde as partes definiam-se como demandante e demandado. A forma de ação em juizo determinava modo de proceder

12) Ver: Louis Rolland - PRECIS DE DROIT ADMINISTRATIF; Louis Trotabas ELEMENTS DE DROIT PUBLIC ET ADMINISTRATIF. 
judicial. O Estado, pessoa jurídica de direito público-político, sôbrepunha-se como fator da lei aos interêsses particulares.

Quando o cidadão julgava-se ofendido em seu direito com relação ao Estado, o recurso estava sempre na discussão e julgamento do protesto interposto. Os casos, não obstante, não eram nada comuns. $O$ poder de govêrno agia da forma que meIhor entendia, cedendo terras, tomando-as, ocupando-as e ceđendo-as novamente à terceiros.

Quasi tôda vida o homem tem sido esta:

- de luta contra a guerra e os regimens de excecão. - de luta contra o poder constituido, - o mesmo poder que estabelece o princípio da coisa julgada e a norma do direito adquirido.

Porisso, o procedimento administrativo é conquista lenta dos tempos que passam. $\mathbf{E}$ com o procedimento, também o direito Processual Administrativo. O Estado que regula e aplica a leı não pode violá-la, — ou exceder-se em seu direito em ofensa aos direitos do cidadão, - aqueles direitos chamados de certos é incontestáveis.

\section{IX}

Aceitamos como opinião generalizada:

- o procedimento civil serve de exemplo ao procedimento administrativo.

Isso não está impedindo porém que após a penetração de domínio próprio, o Direito Administrativo elabore para si mesmo modo especial de agir ou atividade orientada no sentido do seu fim de vida.

O decidido, - informa Spiegel, - é que essa transformação do direito Civil existe, - existe sob a influência de princípios administrativos que atingem a própria ordem privada.

Bem o sabemos: isolar o Estado, não é só impossível, como inútil, - o Estado em sua função social, como núcleo irradiador de fôrça, - ou como centro catalizador de equilíbrio e de contrôle.

Assim como os práticos, - escreve o professor da Universidade de Praga, - consideram o procédimento civil como o 
modêlo de elaboração do procedimento administrativo, assim os teóricos são de parecer que é preferivel fazer de base do procedimento administrativo, - o procedimento civil.

A questão, como observamos, de qualquer lado, permanece tão sòmente uma.

Otto Mayer, procurando ser clàro em problema abstrato, traz à luz dois elementos substanciais, - elementos jurídicos substanciais que tanto pertencem hoje ao processo civil como ao processo administrativo:

- o elemento de procedimento declarativo; e

- o elemento de procedimento executivo:

E Spiegel, outra vez, quem doutrina:

- o objetivo do procedimento em sua primeira etapa vai até o pronunciamento da sentença; pronunciada a sentença, ela se constitui em caminho do procedimento subsequente.

Mayer afirma acreditando:

- em relação ao processo civil, o ato administrativo, pode ser a sentença reguladora.

Nesse ponto não aceitamos o ilustre professor alemão. Otto Mayer justificou demasiado. Ato administrativo não corresponde à sentença civil e penal. Mesmo aplicando não traz julgamento. Perdeu-se Mayer pelo exagero do real.

Sim, - porque para Otto Mayer, nada há fora do real. Tanto que assim define o ato administrativo: sentença de autoridade que determina, em cada caso concreto, o que DEVE SER direito (13).

Mas aí está o exemplo da Inglaterra:

- a determinação processual do que DEVE SER direito compete aos tribunais, - não às autoridades administrativas.

Ludwig Spiegel orienta :

13) Fritz Fleiner - DROIT ADMINISTRATIF ALLEMAND; Mayer LE DROIT ADMINISTRATIF ALLEMAND; também Ludwig Spiegel - ob. cit.; tão pouco existe um tipo normal de procedimento civil, a não ser que se identifique a jurisdição contenciosa com a jurisdição civil geral (Spiegel - ob. cit. - p. 95). 
- na sua inferioridade com respeito aos tribunais, a administração não deve pretender realizar atos com a pretensão da equivalência às sentenças judiciais.

Os poderes são diferentes na sua harmonia constitucional. O processo administrativo é modo de ser ou proceder fora da esfera jurisdicional da justiça aplicada pelos tribunais.

É modo de ser da administração.

\section{$\mathrm{X}$}

Eștá provadamente claro:

- o procedimento da administração segue modelo normativo do procedimento civil e penal, - é método como orientação sem o espirito jurídico coativante.

Bernatzik, no entanto, busca como ponto relacional lógico a figura da coisa julgada (14).

Mas o problema não está assim jurìdicamente situado. 0 ato administrativo não presupõe limite de recurso, - nunca corresponde ou subentende à coisa julgada.

Aceitar para o ato administrativo o radicalismo da tese da coisa julgada, será forçar o enquadramento do Direito Administrativo nas linhas de limite do Direito Civil.

Por outro lado, e para conclusão, convém admitir esta verdade histórica :

- o Direito Civil não possue essa capacidade tão generalizadora... Longe disso. Possue paisagem própria e dentro dessa paisagem está a sua razão social de ser.

A diversidade de fenômeno obriga solução de procedimento diverso e variável. Tudo é questão de técnica jurídica peculiar. E técnica jurídica peculiar que ganha maior expressão no Direito Administrativo, através atos públicos ou privados da administração, - da administração como exteriorizaçẩo $d a$ vontade do Estado nas suas relações com o cidadão e a sociedade.

14) Spiegel - ob. cit.; Manoel de Oliveira Franco Sobrinho - DO CONCEITO DO CONTRATO ADMINISTRATIVO - Ctiba, 1937. 